\title{
Miscibility and thermal properties of poly(vinylpyrrolidone-vinyl acetate)/lamivudine and tenofovir binary blends prepared by hot melt extrusion
}

\begin{abstract}
Preparation of amorphous solid dispersions (ASD) by hot melt extrusion (HME) of poly(vinylpyrrolidone-vinyl acetate) (Kollidon) and the active pharmaceutical ingredients (API) Lamivudine (3TC) and Tenofovir Disoproxyl Fumarate (TDF) was investigated aiming to study their miscibility and thermal behavior. These two drugs are currently used as drugs in first line treatment of patients with Acquired Immunodeficiency Syndrome (AIDS). In order to predetermine parameters for extrusion and the maximum concentration of API to be used without any recrystallization, binary blends were first processed in the mixing chamber at $130^{\circ} \mathrm{C}$ using a roller type rotor at 10,20 and $30 \mathrm{rpm}$ for $7 \mathrm{~min}$, giving rise to ASD of both API, at least up to $20 \mathrm{wt} \%$ of the drug. Both 3TC and TDF were then extruded individually with Kollidon in a single screw extruder. HME produced ASD with high concentration of both Kollidon/API combinations, being part of the API soluble in the polymer matrix. From HME, Kollidon/3TC forms ASD in concentration up to $50 \mathrm{wt} \%$, but from $30 \mathrm{wt} \% 3 \mathrm{TC}$, the ASD has no time stability, showing recrystallization in less than 5 months, while the Kollidon/TDF system forms ASD up to $30 \mathrm{wt} \%$ of TDF, but it has aging stability inferior to 4 months.
\end{abstract}

Keywords: active pharmaceutical ingredients, hot melt extrusion, lamivudine, pvp, solubility, tenofovir disoproxil fumarate
Volume 10 Issue 3 - 202I

Marcos L Dias,' Lucyenne S Barbosa, Rodrigo B Anjos, ${ }^{3}$ Adriana PD Baptista, ${ }^{3}$ Fabio ML Dantas ${ }^{3}$

'Universidade Federal do Rio de Janeiro (UFRJ), Instituto de Macromoléculas Professora Eloisa Mano (IMA), Av. Horácio Macedo 2030, Centro de Tecnologia, Bl.J Cidade Universitária, Rio de Janeiro, Brazil

${ }^{2}$ Farmanguinhos/Fiocruz,Av Comandante Guarany, 447 Pharmaceutical Development, Jacarepaguá, Rio de Janeiro, Brazil ${ }^{3}$ National Institute of Technology (INT)-LAMAP,Av. Venezuela, 42, Centro, Rio de Janeiro, Brazil

\section{Correspondence: Marcos L Dias, Universidade Federal do Rio de Janeiro (UFRJ), Instituto de Macromoléculas Professora Eloisa Mano (IMA),Av. Horácio Macedo 2030, Centro de Tecnologia, Bl.J Cidade Universitária, Rio de Janeiro, Brazil, Emailmldias@ima.ufrj.br}

Received: May 02, 2021 | Published: May 27, 2021
Abbreviations: AIDS, acquired immunodeficiency syndrome; API, active pharmaceutical ingredients; ASD, amorphous solid dispersions; HME, hot melt extrusion; Kollidon, poly(vinylpyrrolidone-vinyl acetate); 3TC, lamivudine; TDF, tenofovir disoproxyl fumarate; XRD, X-ray diffraction

\section{Introduction}

Although the extrusion process is known since 1930, application in the pharmaceutical industry, which adopted the denomination Hot Melt Extrusion (HME), has grown only in recent years. HME has been applied mainly in preparations involving polymers and active pharmaceutical ingredients (API), and, in this context, it is an alternative technique to traditional medicine fabrication methods. Literature demonstrates that several pharmaceutical forms can be prepared by HME for controlled drug delivery, like tablets, pellets, transdermal systems, bioadhesive films and implants. ${ }^{1-5}$

One advantage of using HME in medicine preparations is the possibility of producing Amorphous Solid Dispersions (ASD) of polymers and API with enhancement of solubility in the case of low water solubility APIs. ${ }^{6-8}$ However, despite process robustness and reliability of API release profiles, its potential was not completely explored, and the physical behavior of many polymer/API systems obtained by HME are not known.

In Brazil, the drug called Efavirenz is the most used antiretroviral treatment for Acquired Immunodeficiency Syndrome (AIDS) in the beginning of patient treatment, and it is usually employed in combination with the nucleoside analogous inhibitors Lamivudine ((-)-1-((2R,5S)-2-(Hydroxymethyl)-1,3-oxathiolan- 5-yl)cytosine) and Tenofovir Disoproxyl Fumarate (9-[(R)-2-[[bis [[(isopropoxycarbonyl) oxyjmethoxy] phosphinyl]methoxy] propyl] adenine fumarate (1:1)). ${ }^{9}$ Different polymers can be applied in the preparation of ASD by HME, but vinylpyrrolidone based polymers (PVP) have been largely used since better wettability and solubility of several active substances of low solubility in biological fluids can be attained. PVP polymers are marketed as copolymers with different structures and molecular weights that can influence the rate of drug release and, therefore, the application of the ASD. ${ }^{10-14}$

The cocktail of these polymers with the three drugs: Efavirenz, Lamivudine and Tenofovir in tablet form is one of the most import medicine for AIDS treatment presently, and the understanding of the physical behavior of binary polymer/API blends is of large interest. In a previous work, we have investigated the preparation ASD based on blends of poly(vinylpyrrolidone-co-vinyl acetate) (Kollidon)/Efavirenz by HME and reported on the miscibility and thermal behavior of this binary system. ${ }^{15}$ The blends were amorphous materials, showing high miscibility up to $50 \mathrm{wt} \%$ of Efavirenz and high stability. In this work, binary blends of Kollidon with Lamivudine and Tenofovir Disoproxyl Fumarate in concentrations up to $50 \mathrm{wt} \%$ of the API were prepared by HME in a single screw extruder to evaluate the processability, the maximum concentration of API to still have an amorphous dispersion and its thermal properties.

\section{Materials and methods}

\section{Materials}

Lamivudine (3TC) and Tenofovir Disoproxyl Fumarate (TDF) were supplied by Nortec Química, Brazil. Poly(vinylpyrrolidone- 
co-vinyl acetate) (Kollidon VA64) in powder form and nominal molecular weight 50,000 were supplied by Basf, Germany. The chemical structures of the blend components are shown in Figure 1. All substances were used without further purification.



Kollidon VA 64

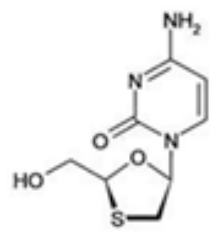

Lamivudine

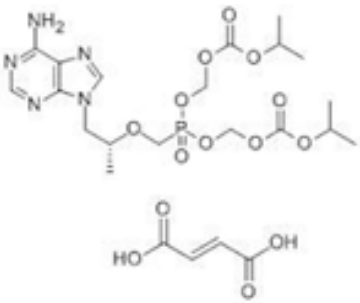

Tenofovir disoproxil fumarate

Figure I Structure of Kollidon VA 64, Lamivudine and Tenofovir disoproxil fumarate.

\section{Blend preparation}

Melt blending was carried out in a HAAKE Rheomix 600 OS using a roller type rotor. Binary blends with concentration of the API from 5 to $50 \mathrm{wt} \%$ was prepared at rotor speed of 10,20 and $30 \mathrm{rpm}$ at $130^{\circ} \mathrm{C}$. The polymer was introduced in the mixing chamber at the prescribed condition and after $2 \mathrm{~min}$, the API was added to the polymer, being the total processing time $7 \mathrm{~min}$. These blends were carried out aiming to have insight on the right concentration to avoid presence of crystalline phase in the blend.

HME of blends of Kollidon/ Lamivudine and Kollidon/ Tenofovir disoproxyl fumarate were performed in a single screw extruder Polylab Thermo Scientific, Haake. Extrusion was carried out in conditions previously tested in a mixer chamber. Polymer/ API blends were extruded at concentrations of 10, 30 and $50 \mathrm{wt} \%$ of each API and screw speed was varied from 20 to $100 \mathrm{rpm}$. The best screw speed and temperature profile was determined based on the final characteristic of the extrudate (haze, bubble formation and filament continuity). The temperatures for the four extruder's zones were TS1 (homogenizing) $=130^{\circ} \mathrm{C}$, TS2 $($ Compression $)=130^{\circ} \mathrm{C}, \mathrm{TS} 3$ (Feeding $)=160^{\circ} \mathrm{C}$ and $\left.\mathrm{TSD} 1(\mathrm{Die})=150^{\circ} \mathrm{C}\right)$ and best screw speed chosen after a screening of conditions $50 \mathrm{rpm}$.

\section{Preparation of physical mixtures}

Polymer/API physical mixtures were prepared by lightly grinding accurately weighed amounts of Kollidon and the API in a mortar for 2 minutes at the required API concentration.

\section{Blend characterization}

X-ray powder diffraction (XRD) was performed on a Rigaku Miniflex using Ni filtered Cuk radiation ( $30 \mathrm{kV}$ and $15 \mathrm{~mA}$ ) in the $2 \mathrm{q}$ range from 3 to $80^{\circ}$, step of $2 \mathrm{q}=0.05^{\circ}$ and acquisition time $1 \mathrm{~s}$. Extrudate was crushed, and the polymer/API system analyzed as powder. A Mettler Toledo 822e DSC was used to determine the glass transition temperatures of Kollidon/ Lamivudine and Kollidon/ Tenofovir blends. Samples weighing around $8.0 \mathrm{mg}$ were analyzed using a heating rate of $10^{\circ} \mathrm{C} / \mathrm{min}$ from $25^{\circ}$ to $200^{\circ} \mathrm{C}$. Two heating run and one cooling run were carried out under a nitrogen atmosphere ( $80 \mathrm{~mL} / \mathrm{min})$. Calibrations for temperature and enthalpy have been performed routinely with Indium. A Mettler Toledo 851e TGA/SDTA was used to determine the weight loss of the polymer, APIs and blends. Samples of around $8.0 \mathrm{mg}$ were analyzed using a heating rate of $10^{\circ} \mathrm{C} / \mathrm{min}$ from $25^{\circ}$ to $400^{\circ} \mathrm{C}$. Analyses were carried out under a nitrogen purge at $50 \mathrm{~mL} / \mathrm{min}$. SEM analyses were carried out using an Oxford low vacuum (300 Pa) SEM equipment with Energy-Dispersive Spectroscopy (EDS) and Wavelength-Dispersive Spectroscopy
(WDS) without any coating, and in a FEI Quanta FEG 450 model with an accelerating voltage of $10 \mathrm{kV}$ with previously coating with gold to observe the surface morphology of the blends.

\section{Results and discussion}

The investigation on the processability of Kollidon/Lamivudine (3TC) and Kollidon/Tenofovir Disoproxyl Fumarate (TDF) was first carried out in a mixer chamber aiming to have insight on the influence of processing condition on the miscibility of the APIs in the PVP based polymer. Drug concentrations from 5 to $50 \mathrm{wt} \%$, rotor speed of 10,20 and $30 \mathrm{rpm}$, processing temperature of $130^{\circ} \mathrm{C}$ and processing time of $7 \mathrm{~min}$ were employed in this study. Subsequently, the materials were processed in a single screw extruder in a temperature close to that used in the processing by melt blending in the mixer chamber to verify if it was possible to use single screw extruder to obtain ASD with Kollidon and these two APIs.

\section{Kollidon/lamivudine system}

Blends of Kollidon/3TC processed in the mixer chamber produced a transparent pale-yellowish solid in most of the tested compositions. Figure 2 shows the X-ray diffraction (XRD) curves of 3TC, Kollidon VA 64, physical Kollidon/3TC mixture containing $50 \mathrm{wt} \% 3 \mathrm{TC}$ and their blends prepared in the melt mixer. Kollidon is an amorphous polymer characterized by a bimodal amorphous halo with maximum intensities at $2 \mathrm{q}=13$ and $22^{\circ}$. In opposition, 3TC shows an XRD pattern with several crystalline reflections which is compatible with a highly crystalline form I with main reflections at $2 \mathrm{q}=20.6,21.4,24.9$ and $26.5^{\circ} \cdot{ }^{16,17}$ As expected, the curve of the $50 \mathrm{wt} \%$ physical mixture is characteristic of a highly crystalline material since no melting of 3TC crystals may occur during the physical mixing process. Nevertheless, blends prepared by melt blending in the melt mixer are amorphous up to $20 \mathrm{wt} \%$ of $3 \mathrm{TC}$, when reflections attributed to $3 \mathrm{TC}$ crystalline phase are seen. The amorphous profiles of XRD curves up to $20 \mathrm{wt} \%$ of $3 \mathrm{TC}$ suggested solubilization of the API or dispersion of 3TC amorphous domains in the amorphous Kollidon matrix up to concentration between 15 and $20 \mathrm{wt} \%$.

XRD curves of the materials obtained from the study performed in the single screw extruder (HME) are shown in Figure 3. Differently from what was observed for blends obtained from melt mixing and for the physical mixtures of both components, extrusion of Kollidon/3TC at the same temperature used in the mixing chamber study $\left(130^{\circ} \mathrm{C}\right)$ resulted in transparent amorphous solid up to $50 \mathrm{wt} \%$ of 3TC. This result means that not only the temperature, but also the shear has an important influence on the state of dispersion/solubilization of 3TC in Kollidon. Although in this work a single screw extruder was 
used to blend the components, the shear attained by the extrusion is significantly higher than that of the mixer, promoting possible complete melting of 3TC and a better dispersion/solubilization of the drug in the Kollidon polymer matrix.

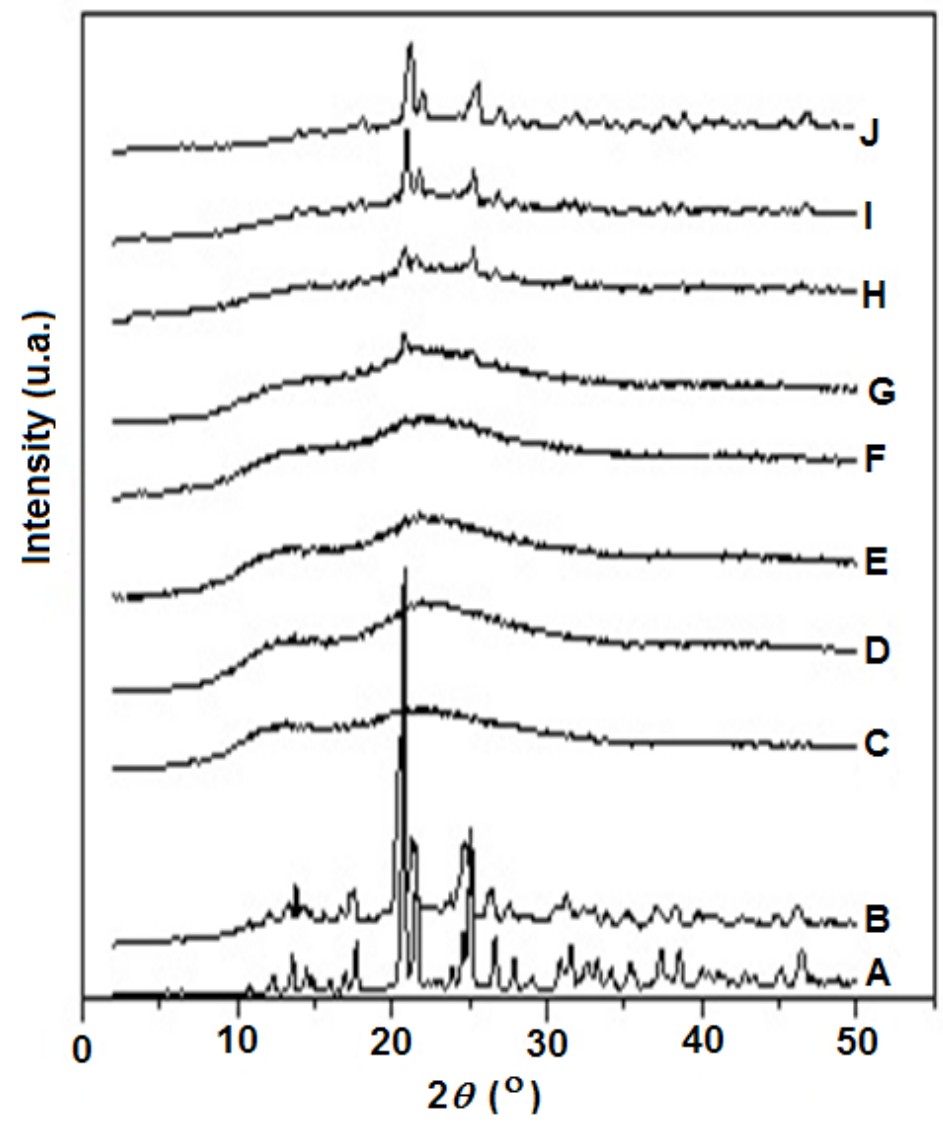

Figure 2 XRD curves of A) $3 T$ C, B) physical mixture of 3TC/Kollidon, C) Kollidon, and Kollidon/3TC blends containing D) 5 wt \%, E) 10 wt\%, F) 15 wt\%, G) 20 $w t \%, H) 30 w t \%$, I) $40 w t \%$ and J) $50 w t \% 3 T C$ obtained in the mixer chamber at $130^{\circ} \mathrm{C}$.

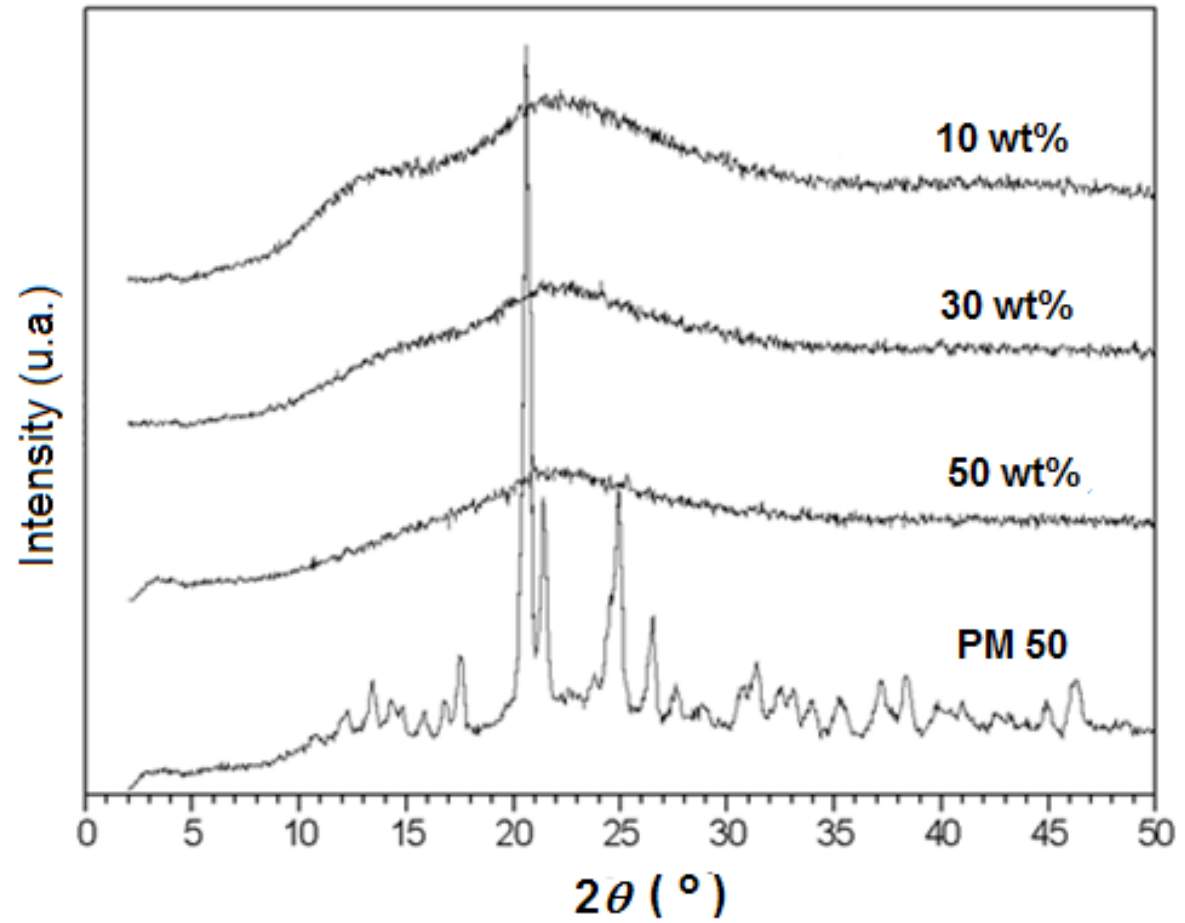

Figure 3 XRD curves of extruded blends of Kollidon/3TC containing 10,30 and 50 wt\% of 3 TC obtained by HME and physical mixture of Kollidon/3TC with 50 wt\% 3TC (PM50).

Citation: Dias ML, Barbosa LS, Anjos RB, et al. Miscibility and thermal properties of poly(vinylpyrrolidone-vinyl acetate)/lamivudine and tenofovir binary blends prepared by hot melt extrusion. J Anal Pharm Res. 2021;10(3):I09-I I6. DOI: I0.15406/japlr.202I.I0.00373 
DSC curves of the first heating of 3TC, Kollidon and their blends from the melt mixing chamber at $30 \mathrm{rpm}$ were obtained. As expected for a highly crystalline material, 3TC showed a single melt endotherm with a high melting temperature $T_{\mathrm{m}}=179.6{ }^{\circ} \mathrm{C}\left(H_{\mathrm{m}}=116.3 \mathrm{~J} / \mathrm{g}\right)$. This $T_{\mathrm{m}}$ is slightly higher than those previously described in the literature $\left(T_{\mathrm{m}}^{\mathrm{m}}=178.6^{\circ} \mathrm{C}\right)$ and can be attributed to Form $\mathrm{I}_{\mathrm{H}}$ crystals (high melting form). ${ }^{17,18}$ All DSC curves of the PVP containing materials showed a characteristic broad endothermic event with maximum intensity around $100{ }^{\circ} \mathrm{C}$ attributed to moisture loss of Kollidon which is a hydroscopic polymer. In addition, the melting peaks related to 3TC appear in the curves of the physical mixture and in blends containing more than 15 wt $\%$, with increasing intensity when the $3 \mathrm{TC}$ concentration increases in the blends. This is an indication that by processing in the mixing chamber, an immiscibility can be detected from this concentration.

From a second DSC heating run after the cooling at $10^{\circ} \mathrm{C} / \mathrm{min}$, the glass transition temperature $\left(T_{\mathrm{g}}\right)$ of the blends were revealed (Table
1). DSC curve of Kollidon showed only a glass transition with $T_{\mathrm{g}}=$ $106.8^{\circ} \mathrm{C}$. For both rotor speed used $(10$ and $30 \mathrm{rpm})$, a significant decrease in the $T_{\mathrm{g}}$ with increasing concentration of $3 \mathrm{TC}$ was observed, suggesting some degree of solubility of 3TC in the polymer phase. No crystallization event was observed during cooling and no melting endotherm was detected in the second heating run of the samples, indicating that by cooling, 3TC cannot crystallize. We concluded from the first heating of the samples that Kollidon/3TC forms immiscible systems from $15 \mathrm{wt} \%$ when prepared from melt mixing at $130^{\circ} \mathrm{C}$, since probably at this processing temperature, the drug cannot melt by the shear effect. Nevertheless, it seems that some solubility and/ or amorphous solid dispersion can be attained if drug melting takes place, since it cannot crystallize on cooling, at least with the cooling rate used in this work $\left(10^{\circ} \mathrm{C} / \mathrm{min}\right)$. Prediction of blends theoretical $T_{\mathrm{g}}$ was not possible, since it was not possible to determine the $T_{\mathrm{g}}$ of $3 \mathrm{TC}^{\mathrm{g}}$, probably due to its high crystallinity.

Table I Main thermal transitions of 3TC, Kollidon and Kollidon/3TC blends obtained by melt blending and HME in the single screw extruder

\begin{tabular}{|c|c|c|c|c|c|c|c|}
\hline \multirow[b]{2}{*}{ Sample } & \multicolumn{4}{|c|}{ Melt blending (Mixer) } & \multicolumn{3}{|l|}{ HME } \\
\hline & $3 T C(w t \%)$ & $\operatorname{Tm}\left({ }^{\circ} \mathrm{C}\right)$ & $\operatorname{Tg}\left({ }^{\circ} \mathrm{C}\right)^{\mathrm{a}}$ & & $\operatorname{Tg}\left({ }^{\circ} \mathrm{C}\right)^{\mathrm{a}}$ & $\operatorname{Tm}\left({ }^{\circ} \mathrm{C}\right)$ & $\mathrm{DH}(\mathrm{J} / \mathrm{g})$ \\
\hline & & & $10 \mathrm{rpm}$ & $30 \mathrm{rpm}$ & - & & \\
\hline 3TC & 100 & 179.6 & - & - & - & - & 116.3 \\
\hline Kollidon & 0 & - & 106.8 & & - & - & - \\
\hline \multirow[t]{5}{*}{ Kollidon/3TC } & 5 & - & 103 & 102 & & - & - \\
\hline & 10 & - & - & - & 102 & - & - \\
\hline & 15 & - & 100 & 100 & - & - & - \\
\hline & 30 & 179.6 & 97 & 98 & 98 & 178 & 0.2 \\
\hline & 50 & 179.6 & 88 & 88 & 88 & 173 & 3.6 \\
\hline
\end{tabular}

a Determined from $2^{\text {nd }}$ heating run; 50 wt\% physical mixture: $T_{m}=179.6{ }^{\circ} \mathrm{C}$ and $T_{g}=99{ }^{\circ} \mathrm{C}$

DSC analyses of Kollidon/3TC blends obtained by hot melt extrusion were also carried out. The two main thermal transitions expected for the two blend components and blends prepared from HME are also resumed in Table 1. Although no evidence of crystal phase was noted by XRD, low intensity melting peaks was observed in the DSC curves for blends with 30 and $50 \mathrm{wt} \%$ of $3 \mathrm{TC}$, but the melting enthalpy for these events was significantly low for these two blends $(\mathrm{H}=0.2$ and $3.6 \mathrm{~J} / \mathrm{g}$, respectively, as compared to $116.3 \mathrm{~J} / \mathrm{g}$ for pristine $3 \mathrm{TC})$.

The $\mathrm{T}_{\mathrm{m}}$ attributed to $3 \mathrm{TC}$ decreased when the content of $3 \mathrm{TC}$ increased in the blend $\left(T_{\mathrm{m}}=177.7\right.$ and $\left.173.2^{\circ} \mathrm{C}\right)$ and the corresponding enthalpy increased as the $3 \mathrm{TC}$ concentration increased. A decrease in the $T_{\mathrm{g}}$ of Kollidon phase was observed as the content of 3TC was increased in the blend, which confirms a certain degree of solubility of 3TC in the polymer phase. These results indicate low amounts of insoluble crystals in the matrix above $30 \mathrm{wt} \%$ and confirmed that by extrusion, it is possible to increase the content of soluble of 3TC in the PVP matrix.

\section{Kollidon/Tenofovir disoproxyl fumarate system}

Melt blending of Kollidon and TDF in the mixing chamber showed in some condition strong odor and development of dark color typical of degradation. It was possible to get only the blends with 5, 10 e 15 $\mathrm{wt} \%(10 \mathrm{e} 20 \mathrm{rpm})$ and $5,10,20$ e $30 \%$ (30 rpm). The blends prepared in other conditions presented a dark-brown aspect which suggested a deterioration during the processing, differently from 3TC blends in which a clear pale yellowish solid was attained in all processing condition. Figure 4 shows the XRD curves of Kollidon/TDF blends containing 5,10 and $15 \mathrm{wt} \%$ obtained in the mixing chamber at $10 \mathrm{rpm}$ and $130^{\circ} \mathrm{C}$. For comparison, the curves of TDF, Kollidon, physical mixture of Kollidon/TDF containing $50 \mathrm{wt} \%$ TDF were also included.

TDF is a crystalline API presenting polymorphism phenomena as many other drugs. Many solid forms have been described in the patent literature, but two are often identified in drug products: Form I and Form A. Although TDF is currently marketed under its most stable form, Form-I, depending on the condition, during formulation this API can be converted partially or totally from Form I to Form A. Crystalline Form I is characterized by XRD peaks at $2 \mathrm{q}=4.9$, $10.2,10.5,18.2,20.0,21.9,24.0,25.0,25.5,27.8,30.1$ and $30.4^{\circ}$ $[19,20]$. The TDF XRD profile presented these peaks suggesting the predominant existence of Form-I. Figure 4 shows also that for all blends analyzed, no crystalline reflections of TDF are seen, indicating that ASD were obtained up to $15 \mathrm{wt} \%$ of TDF. 


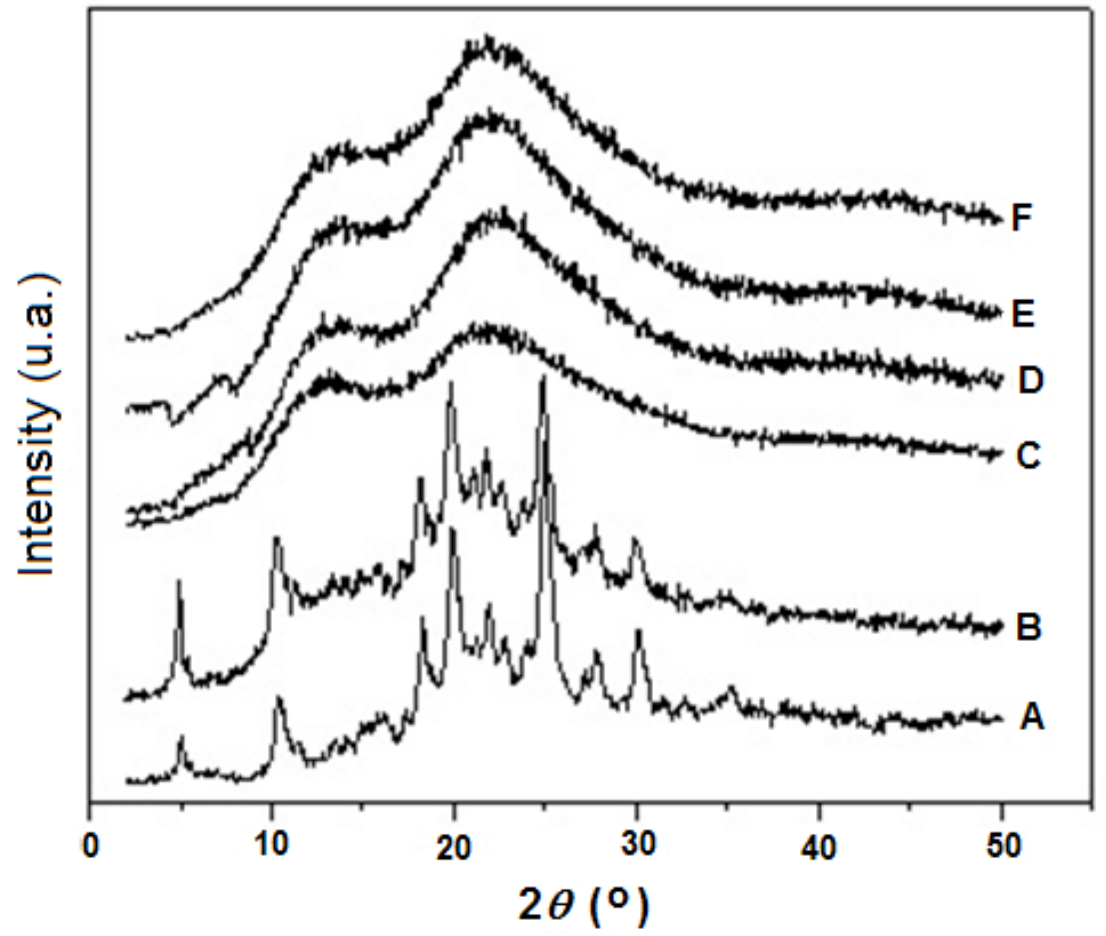

Figure 4 XRD curves of A) TDF, B) physical mixture of Kollidon/TDF 50 wt\%, C) Kollidon, and Kollidon/TDF blends containing D) 5 wt\%, E) I0 wt\% and F) I5 $w t \%$ of TDF obtained in the mixer chamber at $10 \mathrm{rpm}$ and $130^{\circ} \mathrm{C}$.

Kollidon/TDF blends with 10, 30 and $50 \mathrm{wt} \%$ of TDF were also prepared by HME in screw speed from 20 to $150 \mathrm{rpm}$. Due to the difficulty of flowing the blend with $50 \mathrm{wt} \%$, TDF was grounded and the pre-feeding zone was cooled to $20^{\circ} \mathrm{C}$ to avoid heating by the extrusion process and the melting of the powder in the feeding zone with inconvenient adhesion in the extrusion barrel. Figure 5 shows the XRD curves of TDF and of Kollidon/TDF blends containing 10,
30 and $50 \mathrm{wt} \%$ of TDF obtained by HME. The XRD curves of the blends with 10 and $30 \mathrm{wt} \%$ of TDF showed no crystalline reflections of TDF, indicating formation of ASD, while the curve of $50 \mathrm{wt} \%$ TDF presented the crystalline reflections of the API, suggesting the formation of a solid dispersion containing crystalline TDF dispersed in the Kollidon phase.

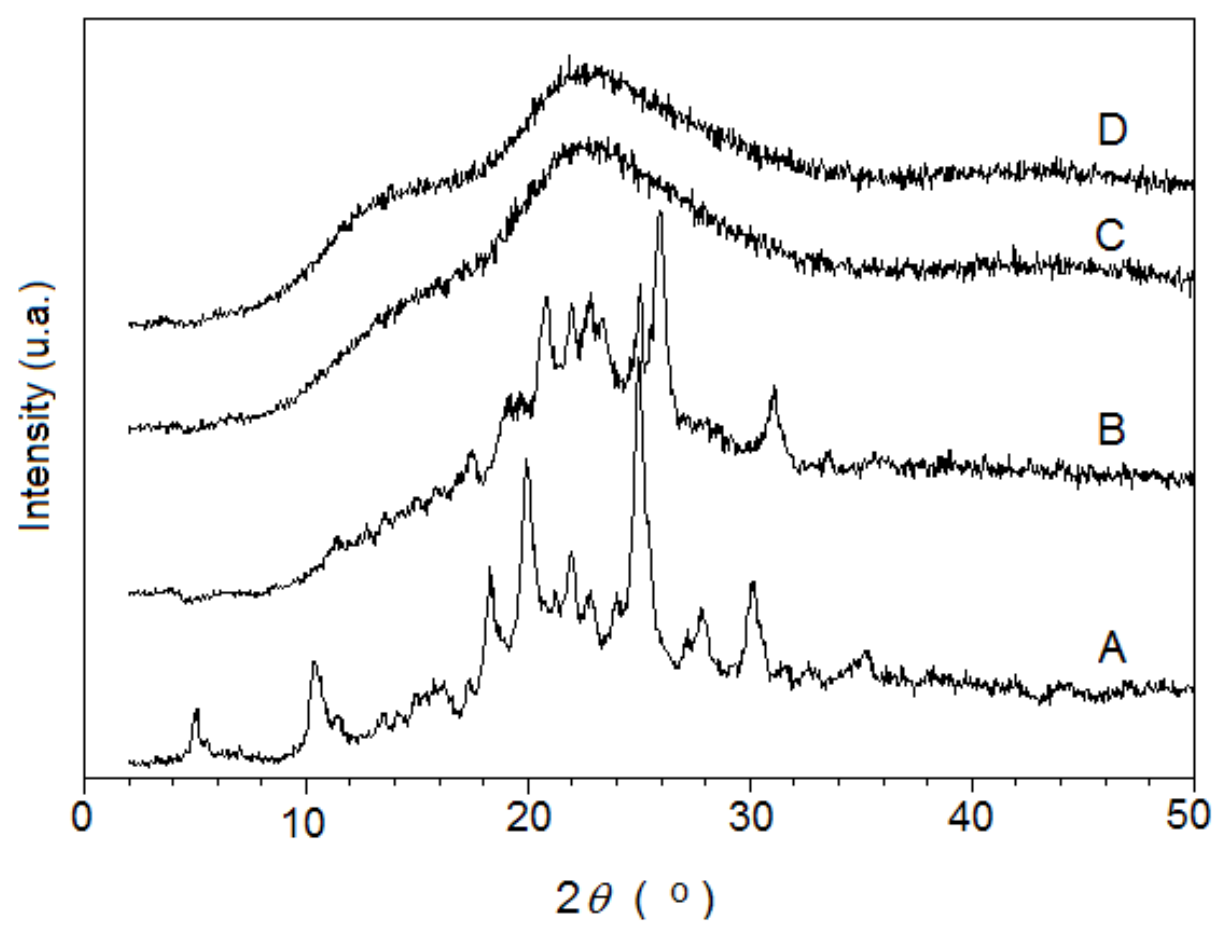

Figure 5 XRD curves of A) TDF, and blends of Kollidon/TDF containing B) 50 wt $\%$ C) 30 wt $\%$ and D) 10 wt $\%$ of TDF obtained by HME. 
The thermal behavior of the Kollidon/TDF blends were analyzed by DSC considering that this technique could give important information on the miscibility of the API in the polymer matrix. ${ }^{21}$ TDF did not present a single well-defined DSC melting peak as 3TC, showing a bimodal melting profile with peaks at 110.6 and $116.1{ }^{\circ} \mathrm{C}$ (expected $\left.T_{\mathrm{m}}=113-118^{\circ} \mathrm{C}\right)$. This melting behavior suggested the existence of at least two crystalline forms. ${ }^{22,23}$

Aiming to determine the glass transition temperature $\left(T_{\mathrm{g}}\right)$ of the drug, another DSC analysis protocol was carried out. Thus, a TDF sample was first heated to $120^{\circ} \mathrm{C}$ at $10^{\circ} \mathrm{C} / \mathrm{min}$, quickly cooled (quenched at about $50^{\circ} \mathrm{C} / \mathrm{min}$ ) and then reheated to $140^{\circ} \mathrm{C}$ at the same heating rate. From this thermal treatment, it was possible to determine the TDF glass transition from the $2^{\text {nd }}$ heating $\left(T_{\mathrm{g}}=28.6^{\circ} \mathrm{C}\right)$. The same procedure was carried out for the blends to determine the $T$ of Kollidon/TDF blends and the influence of melt mixer rotor speed in this transition. Table 2 resumes the values of $T_{\mathrm{g}}$ obtained for the blends prepared using 3 different rotor speed during the processing. It shows that $T_{\mathrm{g}}$ decreases when the content of TDF is increased in the blend. This result demonstrates that a certain fraction of TDF became soluble in the polymer matrix changing its $T_{\mathrm{g}}$. From Table 2 it is also possible to see the influence of the mixer rotor speed in the $T_{\mathrm{g}}$. The increase of rotor speed decreased the $T_{\mathrm{g}}$, indicating that the increase in the shearing promoted by the increase of rotor speed increases the amount of soluble TDF in the Kollidon phase.

Table 2 Influence of mixer rotor speed on the $T_{g}$ of Kollidon/TDF blends

\begin{tabular}{llll}
\hline TDF (wt\%) & \multicolumn{4}{l}{$\operatorname{Tg}\left({ }^{\circ} \mathbf{C}\right) / \mathbf{W t}(\%)^{\mathrm{a}}$} \\
\hline & $10 \mathrm{rpm}$ & $20 \mathrm{rpm}$ & $30 \mathrm{rpm}$ \\
5 & $101.7 / 1.83$ & $99.7 / 2.60$ & $101.7 / 1.87$ \\
10 & $99.1 / 2.84$ & $97.5 / 3.49$ & $97.0 / 3.69$ \\
15 & $96.1 / 4.07$ & $95.1 / 4.5$ & - \\
20 & - & - & $90.5 / 6.59$ \\
30 & - & - & $87.1 / 8.27$ \\
\hline
\end{tabular}

a Weight fraction of TDF from GT equation

The Gordon-Taylor (GT) equation is commonly used to evaluate the miscibility of components in a blend. By this equation it is possible to determine the weigh fraction of one component in the blend from the values of Tg's of the blend and the individual components. ${ }^{24,25}$ The GT equation was used in this work to evaluate the weight fraction of TDS soluble in each Kollidon/TDF blend and the influence of rotation on the TDF solubility, considering the values of Tg's of TDF and Kollidon as 28.6 and $106.8^{\circ} \mathrm{C}$, respectively.

From Table 2 it is evident that the TDF weight fraction found by the GT equation is significantly lower than the nominal TDF concentration, which means that just a certain fraction of TDF became soluble in the matrix. For instance, for the blend containing $15 \mathrm{wt} \%$ TDF prepared at $10 \mathrm{rpm}$, only $4.07 \mathrm{wt} \%$ was found as soluble fraction. As the XRD curves of this blend showed no crystalline peaks, it means that about $10.93 \mathrm{wt} \%$ is not soluble but remains as amorphous domains dispersed in the Kollidon phase, forming an ADS. During the $2^{\text {nd }}$ heating run, TDF also showed a cold crystallization at 91.7 ${ }^{\circ} \mathrm{C}$ from the predominant amorphous state resulted from quenching. In both $1^{\text {st }}$ and $2^{\text {nd }}$ heating run TDF presented bimodal endothermal melting event.

According to the literature, the interconversion between the TDF crystalline forms can occur in ordinary processing conditions, as for instance, by heating and moisture absorption, or even by wet pelletizing. ${ }^{20}$ Form A has a single melting at $T_{\mathrm{m}}=118^{\circ} \mathrm{C}$ while Form I melts at $113.7^{\circ} \mathrm{C} .{ }^{18}$ Considering these previous publications and our results, we concluded that the TDS used in this work is a mixture of polymorphs A and I. The investigation on the miscibility of the blends produced by HME were also carried out by DSC analysis. Table 3 resumes the values of glass transition temperature $(T)$ and melting transition temperature $\left(T_{\mathrm{m}}\right)$ as well as the melting enthalpy $\left(\mathrm{H}_{\mathrm{m}}\right)$ of the blends prepared by HME.

All blends showed no melting peaks, indicating that no evidence of crystalline materials detectable by DSC is present in the blends prepared by HME, what means it was possible to obtain amorphous formulations with high concentration of TDF. It is possible also to note that $T_{\mathrm{g}}$ of Kollidon phase is displaced to lower values, indicating that a considerable fraction of TDF became soluble in the polymer phase. The $T_{\mathrm{g}}$ decreased from $106.8^{\circ} \mathrm{C}$ in the pristine Kollidon to $78.7^{\circ} \mathrm{C}$ for the blends with $30 \mathrm{wt} \%$, and we have found that this $T_{\mathrm{g}}$ was higher than that of the blend with $10 \mathrm{wt} \% \operatorname{TDF}\left(T_{\mathrm{g}}=77.5^{\circ} \mathrm{C}\right)$.

Table 3 Main transitions of TDF, Kollidon and Kollidon/TDF blends obtained by HME in the single screw extruder

\begin{tabular}{llllll}
\hline Sample & TDF (wt\%) & ${\operatorname{Tg~}\left({ }^{\circ} \mathbf{C}\right)^{\mathbf{a}}}$ & Wt (\%) & Tm $\left({ }^{\circ} \mathbf{C}\right)$ & DHm (J/g) \\
\hline TDF & 100 & 28.6 & 0 & $110.6 / 116.1$ & 81.3 \\
Kollidon & 0 & 106.8 & 100 & N.o. & - \\
Kollidon/TDF & 10 & 77.5 & 13.8 & N.o. & - \\
& 30 & 78.7 & 13 & N.o. & - \\
& 50 & 43.6 & & N.o. & - \\
\hline
\end{tabular}



According to the GT equation, $T_{\mathrm{g}}$ will decrease in a manner proportional to the weight fraction of the lower $T_{\mathrm{g}}$ component, if the system is miscible.$^{24}$ The data on Table 3 showed that only about 13 $\mathrm{wt} \%$ of TDF was soluble in the PVP matrix in the blending containing $30 \mathrm{wt} \% \mathrm{TDF}$, which means that a little bit more than half of the concentration (about $17 \mathrm{wt} \%$ ) is dispersed in the polymer phase as amorphous domains. The exceptionally low value of $T_{\mathrm{g}}$ for the 50 wt $\%$ Kollidon/TDF blend is due to the use of the plasticizing Span used to help the processing in this formulation and was not considered for GT equation calculation.

\section{Stability of Kollidon/3TC and Kollidon/TDF}

To investigate the aging stability of ASDs of the binary blends of Kollidon with 3TC and TDF, XRD analyses of blends were carried 
out some months after their preparation by HME. Figure 6(A) shows the curves of Kollidon/3TC containing 10, 30 and $50 \mathrm{wt} \%$ of 3TC just after HME and aged for 5 months at room temperature $\left(25^{\circ} \mathrm{C}\right)$. The samples showed initially no crystalline peak attributed to the API, which indicate the formation of ASD. Nevertheless, after 5 months the blends with 30 and $50 \mathrm{wt} \%$ of $3 \mathrm{TC}$ showed the recrystallization of $3 \mathrm{TC}$ evidenced by the appearance of crystalline peak at $2 \mathrm{q}=$ $21.4^{\circ}$, indicating that for these concentrations the system has no time stability. This observed recrystallization of 3TC would not be expected, considering that kollidon is a rigid polymer matrix at room temperature $\left(T_{\mathrm{g}}=106.8^{\circ} \mathrm{C}\right)$. Nevertheless, this recrystallization can be explained considering that $3 \mathrm{TC}$ has a high crystallization capability and the formed amorphous domains can crystallize during aging.

Figure 6(B) presents the XRD curves of Kollidon/TDF blends obtained just after HME and after 4 months. The curves show that
10 and $30 \mathrm{wt} \%$ Kollidon/TDF blends are amorphous materials, while the blend containing $50 \mathrm{wt} \%$ of TDF presents the crystalline peaks of TDF crystals insoluble in the polymer phase. It is possible to note that, excepting the $50 \mathrm{wt} \%$ of TDF blend, after 4 months the blends with the other concentrations did not show any TDF recrystallization, indicating that they have time stability at least for this period. This result can be interpreted considering that TDF has lower capacity in crystallizing than $3 \mathrm{TC}$, and even if amorphous TDF domains are dispersed in the rigid PVP matrix, it cannot reorganize under the aging condition forming crystals.

We concluded that by HME, Kollidon/TDF can form ASD with up to $30 \mathrm{wt} \%$ of TDF and this ASD has aging stability for at least 4 months. In opposition, Kollidon/3TC forms ASD even with higher concentrations, but from $30 \mathrm{wt} \%$ the ASD has no aging stability, recrystallizing in the period inferior to 5 months.

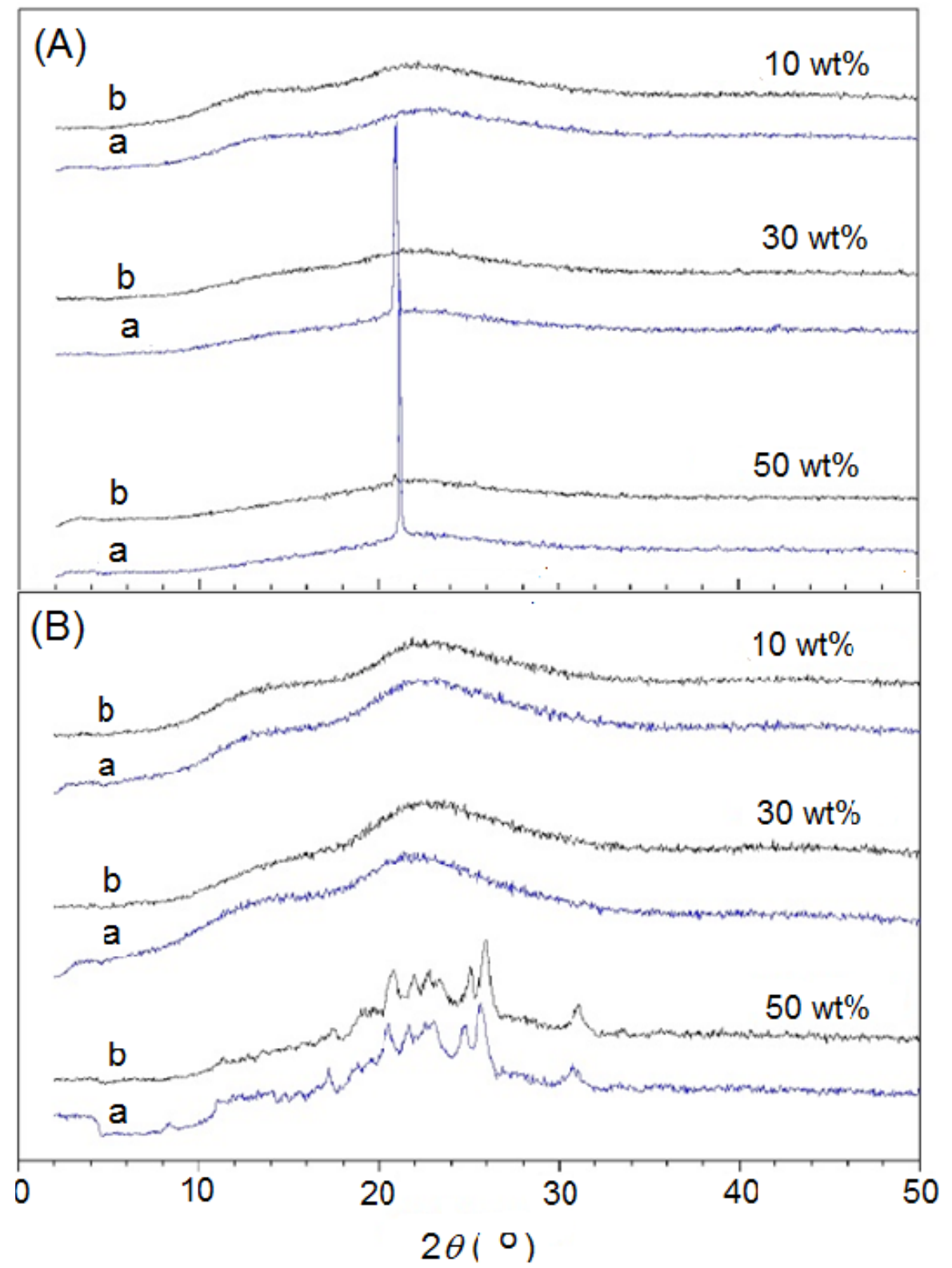

Figure 6 XRD curves of (A) Kollidon/3TC and (B) Kollidon/TDF blends containing 10, 30 and 50 wt\% of the APls obtained by HME (a) sample after 5 months (4 months for TDF) and (b) initial sample. 


\section{Conclusion}

This paper reported the miscibility and thermal behavior of binary blends of poly(vinylpyrrolidone-vinyl acetate) (Kollidon) and the active pharmaceutical ingredients Lamivudine (3TC) and Tenofovir Disoproxyl Fumarate (TDF) prepared by melt blending in mixer chamber and hot melt extrusion (HME). The main aim of the work was to study the formation of Amorphous Solid Dispersions of Kollidon and these two APIs that are currently used as drugs in first line treatment of patients with AIDS. By thermal analyses of extruded samples, it was evident that Kollidon/3TC systems containing 30 and $50 \mathrm{wt} \%$ of $3 \mathrm{TC}$ presents melting peaks, which indicate existence of crystalline material. So, for systems containing $10 \mathrm{wt} \%$ of $3 \mathrm{TC}$ it was possible to have ADS, but for 30 and $50 \mathrm{wt} \%$ systems, solid suspensions were formed, since above $30 \mathrm{wt} \%$ a saturation of the drug occurred in the processing condition used. In opposition, for the Kollidon/TDF system, no melting peak was observed in any concentration up to $50 \mathrm{wt} \%$ of TDF what indicate good degree of interaction between Kollidon and TDF. However, XRD results demonstrated the formation of ASD only for systems containing up to $30 \mathrm{wt} \%$ TDF and a solid suspension for the $50 \mathrm{wt} \%$ blend. From HME, Kollidon/3TC forms ASD in concentration up to $50 \mathrm{wt} \%$, but from $30 \mathrm{wt} \% 3 \mathrm{TC}$, the ASD has no time stability, showing recrystallization in less than 5 months, while the Kollidon/TDF system forms ASD up to $30 \mathrm{wt} \%$ of TDF with aging stability for at least 4 months. Extrusion screw speed influences the blend miscibility since the $\mathrm{T}_{\mathrm{g}}$ of the Kollidon/TDF was reduced with the increase of screw rotation. However, other temperature profiles and higher speed rotation must be tested aiming a higher incorporation of Tenofovir in the polymer. A pre-mixture of Tenofovir with Kollidon should be also investigated in blends with more than $30 \mathrm{wt} \%$ as attempt to improve the incorporation of the API in the polymer. Due to the high degree of crystallinity of Lamivudine, it was not possible to have ASD using the API concentration higher than 10 $w t \%$. The melting point of Lamivudine is considerably higher than the Kollidon Tg, and other temperature profiles would be necessary to improve its dispersion in the polymer.

\section{Research funding}

The authors gratefully acknowledge the support of the Brazilian Agencies: Conselho Nacional de Desenvolvimento Científico e Tecnológico, CNPq (Grant 310917/2014-0 and 307364/2018-6) and Fundação de Amparo à Pesquisa do Estado do Rio de Janeiro, FAPERJ (Grant E-26/201.304/2014 and E-26/202.538/2019) and Farmanguinhos/Fiocruz and National Institute of Technology (INT), Brazil.

\section{References}

1. Breitenbach J, Berndl G, Neumann J. Confocal Raman-Spectroscopy: Analytical Approach to Solid Dispersions and Mapping of Drugs. Proc Control Rel Soc. 1998;16:1109-1113.

2. Breitenbach J. Melt extrusion: from process to drug delivery technology. Eur J Pharm Biopharm. 2002;54:107-117.

3. Chokshi R, Zia H. Hot-Melt Extrusion: from Theory to Application in Pharmaceutical Formulation. Iran J Pharm Res. 2004;3:3-16.

4. Miller DA, McConville JT, Yang W, et al. Hot-melt extrusion for enhanced delivery of drug particles. J Pharm Sci. 2006; 96:361-376.

5. Andrews GP, Jones DS, Diak OA, et al. The manufacture and characterisation of hot-melt extruded enteric tablets. Eur $J$ Pharm Biopharm. 2008;69:264-273.

6. Lakshman JP, Cao Y, Kowalsky K, et al. Application of Melt Extrusion in the Development of a Physically and Chemically Stable High-Energy Amorphous Solid Dispersion of a Poorly Water-Soluble Drug. Mol Pharm. 2008;5:994-1002.
7. Maniruzzaman M, Boateng JS, Snowden MJ. A review of hot-melt extrusion: process technology to pharmaceutical products. ISRN Pharm. 2012;436-763.

8. Jagtap S, Magdum C, Jadge D. Solubility Enhancement Technique: A Review. Int J Pharm Bio Sci. 2013;3:462-475.

9. Gomes ECL, Mussel WN, Resende JM, et al. Chemical Interactions Study of Antiretroviral Drugs Efavirenz and Lamivudine Concerning the Development of Stable Fixed-Dose Combination Formulations for AIDS Treatment. J Braz Chem Soc. 2013;24(4):573-579.

10. Martínez OMC, Rodríguez EC, Martín C. Solid Dispersions of DiflunisalPVP: Polymorphic and Amorphous States of the Drug. Drug Dev Ind Pharm. 2002;28(6):717-725.

11. Lu Q, Zografi G. Phase Behavior of Binary and Ternary Amorphous Mixtures Containing Indomethacin, Citric Acid, and PVP. Pharm Res. 1998;15:1202-1206.

12. El-Hinnawi MA, Najib NM. Ibuprofen-polyvinylpyrrolidone dispersions Proton nuclear magnetic resonance and infrared studies. Int $J$ Pharm. 1987;37(1-2):175-177.

13. Rawlinson $\mathrm{C}$, Williams AC, Williams AC, et al. Polymer mediated disruption of drug crystallinity. Int J Pharm. 2007;336(1):42-48.

14. Altonen J, Alleso M, Mirza S, et al. Solid form screening--a review. Eur J Pharm Biopharm. 2009;71:23-37.

15. Barbosa L, Dias ML, Dantas F, et al. Miscibility and thermal properties of poly (vinylpyrrolidone-vinyl acetate)/ efavirenz glass blends prepared by melt processing. World J Pharm Res. 2014;3:109-123.

16. Kommavarapu P, Maruthapillai A, Allada R, et al. Simultaneous estimation of degree of crystallinity in combination drug product of abacavir, lamivudine and neverapine using X-ray powder diffraction technique. J Young Pharm. 2013;5(4):127-132.

17. Chadha R, Arora P, Bhandari S. Polymorphic Forms of Lamivudine: Characterization, Estimation of Transition Temperature, and Stability Studies by Thermodynamic and Spectroscopic Studies. ISRN Thermodynamics, 2012;671027.

18. Lee EH, Smith DT, Fanwick PE, et al. Metroprolol Fumarate: Crystal Structure from Powder X-ray Diffraction Data and Comparison with the Tartrate and Succinate Salts. Cryst Growth Des. 2010;10:2314-2322.

19. Dova E, Mazurek, JM. Patent WO140302Al, 2008.

20. Sládková V, Dammer O, Kratochvíl B. Solid Forms of Tenofovir Disoproxil Fumarate, Their Mutual Conversion, and Stabilization of Form I in Formulation. J Pharm Sci. 2016;5:3136-3142.

21. Baird JA, Taylor LS. Evaluation of amorphous solid dispersion properties using thermal analysis techniques. Adv Drug Deliv Rev. 2012;64(5):396421.

22. Gomes ECL, Mussel WN, Resende JM, et al. Characterization of Tenofovir Disoproxil Fumarate and Its Behavior under Heating. Cryst Growth Des. 2015;15(4):1915-1922.

23. An JH, Kiyonga AN, Yoon W, et al. Investigation of the Structure and Dynamics of Antiviral Drug Adefovir Dipivoxil by Site-Specific SpinLattice Relaxation Time Measurements and Chemical Shift Anisotropy Tensor Measurements. Molecules. 2017;22:1182.

24. Kalichevsky MT, Jaroszkiewicz EM, Blanshard JMV. A study of the glass transition of amylopectin-sugar mixtures. Polymer. 1993;34:346-358.

25. Babu J, Brostow W, Kalogeras IM, et al. Glass transitions in binary drug + polymer systems. Materials Letters. 2009;63(30):2666-2668.

Citation: Dias ML, Barbosa LS, Anjos RB, et al. Miscibility and thermal properties of poly(vinylpyrrolidone-vinyl acetate)/lamivudine and tenofovir binary blends prepared by hot melt extrusion. J Anal Pharm Res. 2021;10(3):I09-I I6. DOI: I0.15406/japlr.2021.10.00373 